\title{
Leiomyosarcoma of the Female Breast: Report of a Case
}

\author{
Oktay Yener • Fikret Aksoy
}

Received: 23 March 2011 / Accepted: 6 October 2011 /Published online: 23 November 2011

(C) Association of Surgeons of India 2011

\begin{abstract}
Sarcomas of the breast account for less than 1\% of breast tumors. Leiomyosarcoma is an extremely rare form of primary breast sarcoma. We presented here a case of primary leiomyosarcoma of the breast in a 44-year-old woman. We present a case of primary leiomyosarcoma of the breast in a middle-aged female in whom fine-needle aspiration cytologic features uneventful.
\end{abstract}

Keywords Leiomyosarcoma · Breast

\section{Introduction}

Stromal sarcomas of the breast constitute about $1 \%$ of all malignant tumors of the breast [1]. Primary leiomyosarcoma of the breast comprises a rare type of stromal sarcoma of the breast.

Leiomyosarcoma of the breast is rare. In the English language literature, about 16 such cases have been described so far [2]. We present a case of a 44-year-old female patient, whose breast tumor had been present for several months prior to her admission. The mass appeared lobulated on ultrasonography (US). Preoperative US guided fine-needle aspiration biopsy was performed. According to the radiological picture, as well as the age of the patient a phylloid tumor was suggested by the radiologist. The lumpectomy specimen contained a firm lobulated tumor, and microscopic examination revealed a mesenchymal neoplasm.

O. Yener $(\bowtie) \cdot$ F. Aksoy

Department of surgery, Göztepe Training and Research Hospital,

Plaj yolu yıldız sok. Kaya apt. No:16 D:10 caddebostan,, İstanbul, Turkey

e-mail: oktayener@gmail.com

\section{History}

A 44-year-old female patient was admitted to the surgical department, for the presence of a firm lump in her left breast for the past 3 months. US of the left breast revealed a hypoechoic and heterogeneous mass with an irregular shape, rough border, and an irregular boundary echo. The lobulated tumor, $3.5 \mathrm{~cm}$ in diameter, was easily detectable by ultrasound. Peoperative US guided fine-needle aspiration biopsy was performed. According to the radiological picture, as well as the age of the patient excisional biopsy was suggested by the radiologist. A lumpectomy of the left breast was carried out. The subsequent histological diagnosis was stromal sarcoma with leiomyosarcomatous pattern. Radiotherapy was used for the adjuvant therapy. Twelve months later, positron emission tomographycomputed tomography and whole body bone scintigraphy was normal.

\section{Pathological Findings}

Microscopically, the tumor resected with mastectomy was a hypercellular nodule, and was composed of pleomorphic and hyperchromatic spindle-shaped cells arranged in an interdigitating fascicle. The tumors were circumscribed microscopically and were mild hypercellular nodules. Their nuclei were spindle shaped and showed mild to moderate atypia. Few mitoses were seen, and the surgical margins were free of tumor cells (Figs. 1 and 2).

\section{Discussion}

Primary sarcoma of the breast is an unusual condition that accounts for less than $1 \%$ of all breast malignancies and less 


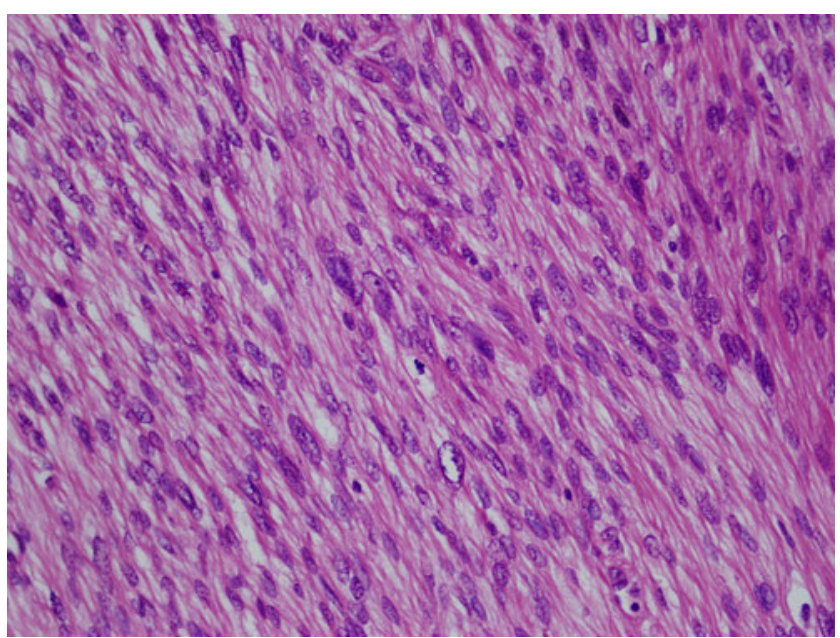

Fig. 1 Microphotograph of leiomyosarcoma. Hematoxylin and eosin stain demonstrates a highly cellular, pleomorphic, and spindle-shaped tumor with few mitotic figures $(400 \times)$

than $5 \%$ of all soft tissue sarcomas. Breast leiomyosarcomas are rare, with only 16 case reports published to date [3].

Waterwarth et al. [4] reported the first convincing case of leiomyosarcoma of the breast in 1968. Although this tumor was reported as fibrosarcoma, the tumor revealed typical light and electron microscopic features of the classic leiomyosarcoma. The mean age of the patients has been reported to be 55.5 years (range, 24-86 years). The tumors tend to present as large masses, with the mean size of $4.7 \mathrm{~cm}$ (range, 1-9 cm). Most patients are females, but at least in two of the reported cases, tumor occurred in the male breast. Nearly half of the tumors are in or near the nipple. In most cases, the tumors are most likely to originate from the blood vessels or the smooth muscle of the nipple-areola complex. Most leiomyosarcomas of the

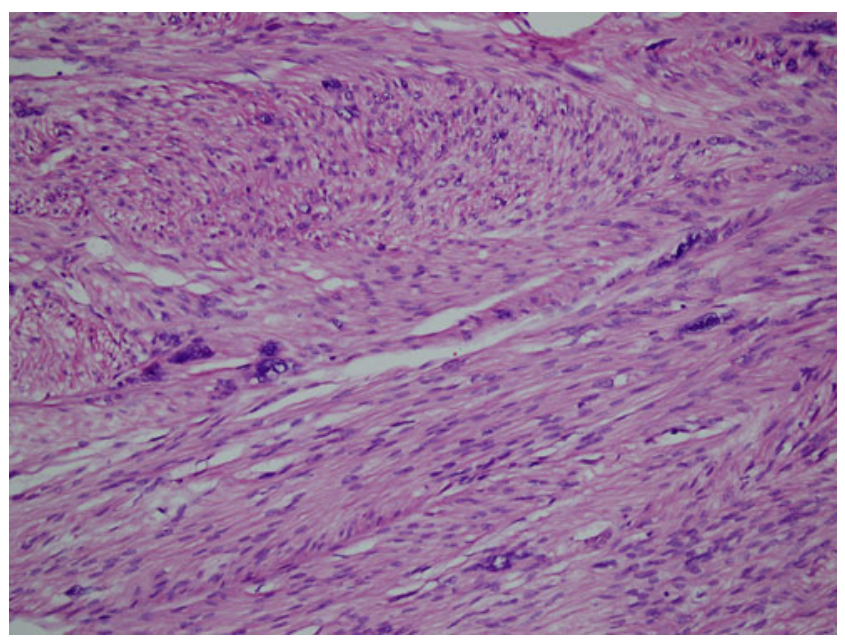

Fig. 2 Microphotograph of leiomyosarcoma. Hematoxylin and eosin stain demonstrates a highly cellular, pleomorphic, and spindle-shaped tumor with few mitotic figures $(400 \times)$ breast are well-circumscribed tumors. Microscopically, the tumors are composed of pleomorphic and hyperchromatic spindle-shaped cells arranged in an interdigitating fascicle. The cytological features reported were hyperchromasia in the nuclei, pleomorphism, and mitosis [2]. Nascimento et al. reported, the mitoses of the tumors ranged from 2 to 21 per 10 high-power fields (HPF) with an average of 10 mitoses. Nascimento has proposed that all recurring tumors that have two mitotic figures per $10 \mathrm{HPF}$ should be considered leiomyosarcomas [5]. Ciatto et al. suggested that the presence of three mitotic figures per $10 \mathrm{HPF}$ is sufficient to designate sarcomas. Primary leiomyosarcoma of the breast is also a very rare tumor and less than 20 well documented cases have been reported in the literature [6].

It presents as a firm lobulated mass and resembles clinically a malignant phyllodes tumor. It is difficult to establish a diagnosis of this rare tumor by fine-needle aspiration cytology. Conventionally, the diagnosis of leiomyosarcoma of the breast is made on postoperative specimens by using immunohistochemical stains. The malignant spindle cells of the tumor are immunoreactive for smooth mucle actin (SMA), vimentin, and desmin and negative for epithelial markers and growth factor receptors $[7,8]$.

Leiomyosarcomas of the breast are rare neoplasms that either arise from the smooth muscle cells lining the blood vessels or from stromal mesenchymal cells [9]. Breast sarcomas are treated by the same principles used in other sarcomas. Thus, wide local excision/lumpectomy or mastectomy with or without radiotherapy are used. Lymphatic spread and nodal metastasis are not the features associated with these neoplasms. Axillary nodal metastasis occurs in less than $10 \%$ of breast sarcomas, making sentinel lymph node biopsy or axillary lymph node dissection unnecessary [10].

Leiomyosarcoma is a rare malignant tumor of the breast. Surgical treatment is the mainstay of therapy. Axillary dissection, chemotherapy, and radiotherapy have not been shown to improve the rates of disease-free or overall survival. Because of the risk of late recurrence, long-term follow-up is necessary.

\section{References}

1. Liang WC, Sickle-Santanello BJ, Nims TA, Accelta PA (2003) Primary leiomyosarcoma of the breast: a case report with review of the literature. Breast J 9:494-496

2. Ugras S, Dilek ON, Karaayvaz M, Dilek H, Peter O, Barut I (1997) Primary leiomyosarcoma of the breast. Surg Today 27:1082-1085

3. Shinto O, Yashiro M, Yamada N, Matsuoka T, Ohira M, Ishikawa $T$ et al (2002) Primary leiomyosarcoma of the breast: report of a case. Surg Today 32:716-719 
4. Waterworth PD, Gompertz RHK, Henncssy C (1992) Primary leiomyosarcoma of the breast. Br J Surg 79:169-171

5. Nascimento AG, Rosen PP, Karas M, Caron AG (1979) Leiomyoma of the nipple. Am J Surg Pathol 3:151-154

6. Ciatto S, Bonardi R, Catalioni L, Cardona G (1992) Sarcomas of the breast: a multicenter series of 70 cases. Neoplasma 39:375-379

7. Lawrence W Jr, Donegan WL, Natarajan N (1987) Adult soft tissue sarcomas: a pattern of care survey of the American College of Surgeons. Ann Surg 205:349-359
8. Arista-Nasr J, Gonzalez-Gomez I, Angeles-Angeles A (1989) A Primary recurrent leiomyosarcoma of the breast. Am J Clin Pathol 92:500-505

9. Wong L, Huang P, Luh S, Huang CS (2008) Primary leiomyosarcoma of the nipple-areola complex:report of a case and review of literature. J Zhejiang Univ Sci B 9(2):109-113

10. Szekely E, Madaras L, Kulka J, Járay B, Nagy L (2001) Leiomyosarcoma of the female breast. Pathol Oncol Res 7:151153 